\title{
A construção de um espaço literário para vozes afro-brasileiras: Terra Negra, de Cristiane Sobral, e a editora Malê
}

\author{
The Construction of a Literary Space for Afro-Brazilian Voices: \\ Terra Negra, by Cristiane Sobral, and the Publishing Company Malê \\ La construcción de un espacio literario para voces afrobrasileñas: \\ Terra Negra, de Cristiane Sobral, y la Editora Malê \\ Camila Marchesan Cargnelutti
}

\section{Resumo}

Neste artigo, abordamos algumas reflexões sobre o mercado editorial brasileiro, buscando compreender os aspectos complexos - econômicos, ideológicos, políticos e históricos - que perpassam os campos da literatura e da edição de livros no país, particularmente os de poesia afro-brasileira. Para tanto, focamos no caso de uma pequena editora, a Malê, especializada na publicação de escritores e escritoras afro-brasileiros/as, e em uma de suas obras, Terra Negra (2017), de Cristiane Sobral. Na análise, atentamos especialmente para a construção poética do poema "350 metros", considerando-o como um poema-testemunho, construído, portanto, a partir da inter-relação entre elementos referenciais e ficcionais, que buscam fazer emergir vozes de mulheres negras silenciadas, tanto no poema quanto no campo literário e editorial.

Palavras-chave: poesia afro-brasileira, literatura de autoria feminina, mercado editorial, testemunho.

\section{Abstract}

In this paper, we discuss some reflections on the Brazilian publishing market, trying to understand the economic, ideological, political and historical aspects that permeate the fields of literature and book publishing in the country, particularly, the Afro-Brazilian poetry. We focus on the case of a small publishing house, Malê, specializing in the publication of Afro-Brazilian writers, and on Terra Negra (2017), by Cristiane Sobral. We pay special attention to the construction of the poem "350 metros", approaching it as a testimonial poem, built, therefore, from the interrelations between referential and fictional elements, which seek to showcase voices of silenced black women, both in the poem and in the literary and editorial field.

Keywords: Afro-Brazilian poetry, literature of female authorship, editorial market, testimony.

\begin{abstract}
Resumen
En esta investigación, abordamos algunas reflexiones sobre el mercado editorial brasileño, buscando comprender los aspectos complejos económicos, ideológicos, políticos e históricos - que atraviesan los campos de la literatura y de la edición de libros en el país, particularmente los de poesía afrobrasileña. Para ello, nos enfocamos en el caso de una pequeña editorial, Malê, especializada en la publicación de escritores y escritoras afrobrasileños/as, y en una de sus obras, Terra Negra (2017), de Cristiane Sobral. En el análisis, nos fijamos especialmente en la construcción poética del poema "350 metros", considerándolo como un poema-testimonio, construido, por lo tanto, a partir de la interrelación entre elementos referenciales y ficticios, que buscan hacer emerger voces de mujeres negras silenciadas, tanto en el poema como en el campo literario y editorial.
\end{abstract}

Palabras-clave: poesía afrobrasileña, literatura de autoría femenina, mercado editorial, testimonio.

\footnotetext{
* Universidade Federal de Santa Maria (UFSM), Santa Maria, RS, Brasil. Dorcid.org/0000-0002-0936-5124. E-mail: camila.m.cargnelutti@gmail.com
} 


\section{Sobre o mercado e as tentativas de ruptura e de inserção}

Historicamente, as relações que perpassam os campos das artes, da literatura e do mercado são complexas e diversas, passando, por exemplo, pela sujeição dos artistas e literatos ao patrocínio e aos propósitos de seus patronos ou mecenas até o século XVII e, posterior e mais abertamente, à própria concepção da arte como universo essencialmente atrelado aos pressupostos da economia mercantil. Como consequência, operou-se, então, na visão de Adorno e Horkheimer (1947/2002), no ensaio intitulado "O Iluminismo como mistificação das massas", uma transformação da arte em mercadoria a ser consumida. Em meio a essas interrelações, as atividades de editoração, principalmente de obras literárias, revelam aspectos complexos desse embate - as relações entre valores estéticos, valores econômicos e valores políticos que determinam ou não a publicação de uma obra ou de um(a) autor(a).

O cenário atual, no âmbito das discussões e teorias literárias, demonstra uma abertura muito maior para a reflexão sobre os elementos ideológicos, econômicos, políticos, sociais e históricos que se manifestam na definição dos critérios de julgamento mobilizados para atribuir o valor literário e/ou estético de uma obra ${ }^{1}$ e, consequentemente, para sua publicação no mercado editorial. ${ }^{2}$ A formação desses critérios de atribuição de valor referentes à literatura é variável, podendo se modificar com o passar do tempo, visto que "valor", na concepção de Terry Eagleton (2006, p. 17), é entendido como um termo transitivo: "significa tudo aquilo que é considerado como valioso por certas pessoas em situações específicas, de acordo com critérios específicos e à luz de determinados objetivos".

Esses valores, portanto, além de serem historicamente mutáveis, não são baseados apenas em supostas preferências individuais. Os juízos de valor literário relacionam-se muito proximamente ao sistema econômico e às ideologias ${ }^{3}$ sociais de determinado período: "eles se referem, em última análise, não apenas ao gosto particular, mas aos pressupostos pelos quais certos grupos sociais exercem e mantêm o poder sobre outros" (Eagleton, 2006, p. 24). Concepção semelhante foi desenvolvida anteriormente por Adorno (1949/2002), no ensaio intitulado "Crítica cultural e sociedade". Nesse texto, Adorno discute as relações entre a publicação de obras culturais/artísticas e a reprodução de categorias sociais dominantes e do status quo, além de ressaltar como os juízos de valor envolvidos nesse processo estão diretamente ligados ao sistema econômico e ao mercado: "na destilação desses 'valores' - termo no qual ecoa, não por acaso, a linguagem da troca de mercadorias - a cultura se entrega às determinações do mercado" (Adorno, 2002, p. 48).

Com uma visão não tão determinista quanto a do autor e na contramão das principais determinações do mercado, ainda que isso não signifique manter-se em um lugar totalmente apartado dele, as pequenas editoras têm, cada vez mais, encontrado seus espaços próprios de criação, inserção, circulação e expansão. Entre estas, destacam-se principalmente dois tipos, na concepção de Luciana di Leone (2014): as editoras que buscam brechas e espaços ainda não ocupados pelos grandes grupos editoriais - não necessariamente possuindo uma posição estética definida, mas construindo suas estratégias de publicação e edição a partir da ocupação desse nicho de mercado; e aquelas que focam em um projeto estético e de circulação bem definido. A partir desses dois tipos mais gerais, existem inúmeras misturas, formando pequenas editoras nacionais.

No contexto brasileiro, a editora Malê configura-se como uma editora pequena e relativamente nova, que se constitui a partir de um misto desses dois tipos. A Malê apresenta um projeto estético

\footnotetext{
${ }^{1}$ Sobre essa discussão, ver também o capítulo "Valor", no livro O demônio da teoria, de Antoine Compagnon (2001), e Estética e política do romance contemporâneo, de Michel Peterson (1995).

${ }^{2}$ Em pesquisa intitulada "A literatura no mercado editorial: um estudo da visão comercial sobre a literatura", Renata Mendonça Machado (2008) aborda alguns aspectos da sociedade contemporânea e da literatura, a partir da relação que se estabelece entre os interesses comerciais (de mercado) e a arte literária.

${ }^{3}$ De acordo com Eagleton (2006, p. 22-23), a ideologia não diz respeito apenas a crenças profundamente enraizadas e muitas vezes inconscientes, mas, particularmente, refere-se aos "modos de sentir, avaliar, perceber e acreditar, que se relacionam de alguma forma com a manutenção e reprodução do poder social".
} 
definido e uma linha editorial bastante clara: possibilitar um espaço editorial para a publicação de textos literários em língua portuguesa, escritos por autores e autoras negros/as brasileiros, africanos e da diáspora, em gêneros como conto, poesia, romance, crônica, ensaio, crítica textual e roteiro. Simultaneamente, a Malê surge a partir da percepção de um nicho no mercado editorial, diante da dificuldade de encontrar livros de autores negros em circulação. ${ }^{4}$ A partir dessa constatação, a editora formou-se em 2016 e, conforme descrição disponível em seu site, ${ }^{5}$ define-se como uma editora que busca colaborar para a ampliação da diversidade do mercado editorial brasileiro, publicando autores com o objetivo de garantir-lhes visibilidade, assessoramento editorial e obras com design, produção gráfica e impressão de qualidade.

Essas editoras pequenas também podem ser compreendidas como independentes; porém, isso não significa que elas se encontram em um lugar completamente à parte das leis que regem o mercado, a economia e a sociedade como um todo. Conforme explicação de Leone (2014, p. 77), a independência que qualifica os projetos destas pequenas editoras, assim como a Malê, é bastante plural. Dessa forma, para a autora, elas podem ser entendidas como independentes em relação aos grandes conglomerados editoriais e, em certa medida, ao próprio mercado; independentes de um processo de globalização cultural que visa à homogeneização; independentes de uma imagem do outro previamente determinada e fixa; e também independentes perante a mesmice de publicações semelhantes.

Essa discussão é complexa e, apesar de as pequenas editoras poderem ser classificadas como independentes em algum grau a partir dessa concepção de Leone, é importante lembrar que elas também estão inseridas no mercado, em maior ou menor medida, e, assim como as editoras que compõem grandes conglomerados, também necessitam dele (de vendas, de público, de consumidores, de publicidade etc.) para continuarem publicando as obras literárias afins a seus projetos editoriais. Em relação às obras que compõem os catálogos dessas pequenas editoras, e especialmente as de poesia, a autora ressalta como elas convidam a olhar para além do texto instigam o leitor a perceber o contexto e aquilo que fica oficialmente fora da obra, mas que também faz parte da sua composição:

O que os [catálogos] destas editoras dizem, especialmente aquelas que se dedicam à poesia, é algo que vai além dos seus títulos, além dos próprios textos, além do especificamente poético. Os catálogos de muitas destas editoras, além de convidar a uma leitura dos textos, convidam a olhar para aquilo que fica de fora do livro, mas o cerca. Os catálogos expõem que a literatura contemporânea também joga nas próprias margens dos textos (Leone, 2014, p. 74).

A editora Malê, aqui especificamente com a publicação do livro de poesias Terra Negra (2017), de Cristiane Sobral, foco deste estudo, é um exemplo representativo dessa tentativa de estímulo ao leitor para que observe também o que está além do livro, sem deixar de atentar profundamente para o texto literário em si. Ou seja, provoca o/a leitor/a a apreender aspectos que, ainda que não estejam explícitos na obra, também colaboram para a sua composição, manifestando o contexto de sua construção - elementos históricos, ideológicos, sociais, econômicos e culturais. Compagnon (2001) afirma que a análise de um determinado texto pressupõe o conhecimento de seu contexto. Nesse sentido, o resgate da conjuntura nas análises literárias, apreendendo autora e obra em articulação com seu contexto histórico-social - espaço de hegemonia de determinadas ideologias -, torna-se fundamental para compreender não somente o texto, como também os mecanismos de exclusão e de silenciamento de determinados discursos literários, processo que historicamente se impôs à literatura de autoria feminina afro-brasileira. Com o movimento de reafirmação de sua linha editorial em cada publicação de autor/a negro/a e com a própria escrita de Cristiane Sobral, mais uma vez, reforça-se a compreensão das obras literárias como situadas em um contexto históricosocial e como resultantes das relações entre autores, intermediários e leitores. Como explica

\footnotetext{
${ }^{4}$ Um dos sócios-fundadores da editora Malê, Vagner Amaro, em entrevista concedida ao jornal $O$ Globo, afirmou: "percebi que há um desinteresse do mercado editorial pelos negros que fazem uma literatura de resistência, ou de combate, ou uma 'contraliteratura', usando nos seus textos temas como o racismo na perspectiva do negro, que impregnam sua literatura da perspectiva do negro, mesmo quando abordam todos os temas comuns das outras literaturas" (Amaro, 2016).

${ }^{5}$ Endereço oficial do site da editora Malê: https://www.editoramale.com/. Acesso em: 15 mar. 2019.
} 
Canclini (2016, p. 86), “os diferentes modos de fazer literatura e de questioná-la estão condicionados pelo momento histórico e pelo enraizamento social da prática literária".

Em consonância com a linha editorial da Malê e com sua definição como editora que busca ampliar a diversidade do mercado editorial brasileiro, pode-se citar algumas de suas iniciativas, que têm sido desenvolvidas desde sua fundação. Além de focar sua atenção na publicação de escritores/as brasileiros/as, africanos/as e da diáspora, a Malê também oferece serviços de assessoramento editorial e de agenciamento literário, com o intuito representar e orientar autores/as em atividades culturais e literárias. Em 2017, criou o selo infantil Malê Mirim, com a proposta de editar livros que abordem temas relacionados à identidade, à alteridade e à valorização das histórias e das culturas afro-brasileiras, indígenas e africanas. A editora Malê também organizou uma festa literária, a "Àjoyò, celebração da literatura afro-brasileira". O evento, realizado em 2016, configurou-se como um espaço de divulgação de autores/as negros/as e de suas obras e contou com leituras dramatizadas, apresentações musicais, lançamento de livros e encontros com escritores/as.

No mesmo ano, foi criado o Prêmio Malê de Literatura, que recentemente divulgou o resultado dos/as vencedores/as da edição de 2019, nas quatro categorias (romance, conto, teses e dissertações de jovens escritores/as negros/as). A ação busca promover a literatura e a leitura, estimular e divulgar a produção literária e contribuir para a igualdade racial, promovendo visibilidade positiva aos/às jovens negros/as. Em 2019, a editora Malê lançou a primeira edição da Mahin - Revista Literária, um espaço para publicação de entrevistas, imagens, resenhas, artigos e perfis, com conteúdos relacionados à literatura, ao mercado editorial, a escritores/as negros/as, a suas histórias, trajetórias e produções literárias. Atualmente, a editora Malê também promove uma série de encontros virtuais, por meio de suas redes sociais, ${ }^{6}$ intitulados "Encontros Literários Malê Online \#ficaemcasa" e "Conexões Literárias - Intelectuais Negras", desenvolvendo um importante trabalho de divulgação de obras e de discussão de temas alinhados com a sua concepção editorial. ${ }^{7}$

\section{Terra Negra e as dificuldades de publicar literatura afro-brasileira}

Lançado em 2017, Terra Negra é o sexto livro 8 publicado pela poeta, atriz, professora e escritora brasileira Cristiane Sobral. Em seu blog pessoal, ${ }^{9}$ a autora assim se autodefine: "sou uma escritora desafiando os padrões. Mulher, negra, suburbana, mãe, esposa. Eu existo nesse país. Tenho muito a escrever". Terra Negra dá continuidade a uma perspectiva estética presente em suas obras anteriores, apresentando um comprometimento com a linguagem e com a construção literária e poética, de maneira a reafirmar a identidade negra, abordar temas muitas vezes silenciados, discutir gênero e raça, resgatar a memória e a ancestralidade, trazer à tona valores culturais e tradicionais. Uma das estratégias mais perceptíveis desse comprometimento poético da autora está justamente no uso de expressões e na escolha do vocabulário, ${ }^{10}$ significativos também por remeterem a línguas ou dialetos de grupos étnicos ou países de África.

\footnotetext{
${ }^{6}$ Os encontros têm contado com a participação virtual de importantes autores/as, como Martinho da Vila, Elisa Lucinda, Tom Farias, Cristiane Sobral, Miriam Alves e Geni Guimarães. As conversas ocorrem principalmente por meio de "lives" na rede social Instagram, no perfil oficial da editora, disponível em: https://www.instagram.com/editoramale/. Também são disponibilizadas no canal da Editora Malê no Youtube, disponível em: https://www.youtube.com/channel/UCs-ksz0OATC-q8TJzK758iQ/featured.

${ }^{7}$ Mais informações sobre as iniciativas desenvolvidas pela editora Malê podem ser encontradas no site oficial, disponível em: https://www.editoramale.com

${ }^{8}$ Alguns títulos da escritora: Não vou mais lavar os pratos (editora Thesaurus, 2010) - poemas; Espelhos, miradouros, dialéticas da percepção (Dulcina, 2011) - contos; Só por hoje vou deixar o meu cabelo em paz (Teixeira, 2014) - poemas; $O$ tapete voador (Malê, 2016) - contos; Olhos de Azeviche (Malê, 2017, coletânea de diversos autores) - contos e crônicas; Terra Negra (Malê, 2017) - poemas; Tainá, a guardiã das flores (2018, em coautoria com sua filha, Ayana Sobral) - infantil; Uma boneca no lixo (escrito em 1998, mas publicado somente em 2018) - dramaturgia; Dona dos ventos (Patuá, 2019) - poesia.

${ }^{9}$ Disponível em: https://cristianesobral.blogspot.com/. Esse espaço contém diversas resenhas sobre as obras da escritora, entrevistas disponíveis no YouTube, vídeos nos quais a autora recita alguns poemas, reportagens em canais de televisão, fotografias e participações em eventos, entre outros materiais.

${ }^{10}$ Apenas a título de exemplificação, citamos algumas palavras utilizadas na obra em análise: tambor, gongá, batuque, preta velha, curumim, erês, pajelança, orixás, candanga, samba, quilombo, caboclo, entidade, ginga etc. É importante ressaltar que, ainda que
} 
Cristiane Sobral publica há duas décadas, tendo iniciado sua carreira escrevendo para os Cadernos Negros. ${ }^{11}$ Sua primeira colaboração ocorreu no ano 2000, na forma de poema, e, desde então, a autora soma mais de uma dezena de contribuições ${ }^{12}$ nesse que se tornou um espaço literário de extrema importância para seu desenvolvimento e sua formação como escritora negra. No entanto, a autora destaca que teve bastante dificuldade com suas primeiras obras, levando mais de dez anos para conseguir publicar Não vou mais lavar os pratos, seu primeiro livro de poemas. Na época, algumas editoras retornavam elogiando sua escrita, porém, recomendando mudanças em seus originais para que se procedesse à publicação: "pediam que tirasse as discussões sobre racismo e negritude e os pontos em defesa da mulher. Eu não aceitei, entendia que ceder seria retirar a essência da minha obra" (Sobral, 2018, n/p.). A afirmação de Sobral é representativa da dificuldade encontrada para adentrar o mercado editorial brasileiro, particularmente quando sua literatura se alinha a perspectivas contra-hegemônicas, como é o caso da autora, ao abordar discussões sobre negritude, raça e gênero.

A decisão de Sobral em não aceitar as mudanças solicitadas pelas grandes editoras - as quais esvaziariam de sentido sua própria escrita, na medida em que silenciariam questões como a reafirmação da identidade negra e discussões sobre feminismo - revela a concepção da autora sobre seu fazer literário também como uma forma de resistência e de enfrentamento em relação a esse tipo de situação, num contexto muito mais amplo de silenciamento histórico de vozes femininas e, duplamente, de vozes femininas $e$ negras. A autora explica: "o fato de conhecer pouquíssimas mulheres negras escrevendo também revelava a dificuldade de adentrar o mercado editorial. A literatura parecia um ambiente destinado aos ricos, homens e brancos" (Sobral, 2018, n/p.).

Para Sobral (2018), a mulher negra escritora ainda não existe para o mercado editorial brasileiro e as poucas exceções que conseguem alcançar algum espaço, na verdade, só confirmam a regra. $\mathrm{O}$ posicionamento da autora traz à discussão problemáticas referentes ao campo editorial de literatura no país. Somadas às dificuldades habituais para inserir-se no mercado editorial (particularmente na edição de poesia), ${ }^{13}$ acrescentam-se ainda, no caso de escritoras mulheres e negras, silenciamentos e exclusões históricas baseadas em questões de gênero e raça. Ao abordar temas relacionados à violência colonial sofrida pelos negros escravizados no contexto brasileiro até o século XIX e os seus desdobramentos visíveis ainda hoje no Brasil, Luiz Silva Cuti (2010, p. 58) corrobora a visão de Sobral ao afirmar que "a feição do racismo à brasileira se pauta por silenciar os discriminados. Essa ideologia vai se imiscuir também na avaliação da arte".

Por racismo, compreendemos, neste estudo, a "tentativa de estigmatizar a diferença com o propósito de justificar vantagens injustas ou abusos de poder, sejam eles de natureza

não sejam palavras de uso exclusivo de grupos étnicos ou de países de África, estas remetem a línguas, dialetos, imaginários e repertórios de origem africana ou afro-brasileira.

11 A série Cadernos Negros, publicada desde 1978, constitui um espaço literário fundamental para a produção de autoria afrobrasileira. Organizada pelo Quilombhoje, Cadernos Negros publica contos e poemas e configura-se como uma fonte histórica e literária essencial para a veiculação e pesquisa artística e cultural afro-brasileira. A publicação é anual e, desde sua origem, mais de 40 volumes já foram publicados, ininterruptamente, entre contos e poemas, simbolizando visibilidade, oportunidade e representatividade para autores/as afro-brasileiros/as.

${ }^{12}$ Segundo pesquisa desenvolvida pelo Portal Literafro - Portal da literatura afro-brasileira, Cristiane Sobral publicou nas seguintes edições de Cadernos Negros: Cadernos Negros 23 (2000); Cadernos Negros 24 (2002); Cadernos Negros 25 (2002); Cadernos Negros (2006); Cadernos Negros 30 (2007); Cadernos Negros, três décadas: ensaios, poemas, contos (2008); Cadernos Negros "Black Notebooks", edição bilíngue com volumes em prosa e poesia (2008); Cadernos Negros 32 (2009); Cadernos Negros 33 (2010); Cadernos Negros 34 (2011); Cadernos Negros 35 (2012); Cadernos Negros 36 (2013); Cadernos Negros 37 (2014); Cadernos Negros 38 (2015); Cadernos Negros 40 (2017). O Portal Literafro é um trabalho organizado pelo Grupo Interinstitucional de Pesquisa Afrodescendências na Literatura Brasileira, constituído em 2001 e sediado no Núcleo de Estudos Interdisciplinares da Alteridade (NEIA), da Faculdade de Letras da Universidade Federal de Minas Gerais (UFMG). Disponível em: http://www.letras.ufmg.br/literafro/autoras/203-cristiane-sobral. Acesso em: 22 maio 2020.

13 Sobre as dificuldades particulares à edição de poesia, Leone $(2014$, p. 79$)$ destaca: "lembremos que a edição de poesia, com algumas exceções de autores consagrados, tradicionalmente tem se restringido à atividade independente por diversos motivos. Entre eles, o mais esgrimido pelos analistas é o baixo lucro do livro de poesia, que afasta o interesse das grandes editoras, principalmente em relação a autores estreantes que nem sequer trariam um capital simbólico considerável". Outra dificuldade apontada pela autora diz respeito ao fato da edição de livros de poemas ser, ainda hoje, considerada um investimento arriscado, por conta de uma "concepção de poesia baseada na sua restrição a um grupo de iniciados" (Leone, 2014, p. 79). 
econômica, política, cultural ou psicológica" (Shohat e Stam, 2006, p. 51). Conforme destacam os autores, é importante ressaltar que, embora qualquer grupo possa ter e manifestar opiniões racistas, não é todo grupo que detém o poder necessário para de fato praticar o racismo, uma vez que, para que ele se concretize, é preciso traduzir uma atitude preconceituosa em uma opressão social - que é, simultaneamente, material e simbólica, manifestando-se ao nível do discurso e da própria literatura.

Da mesma forma, o racismo materializa-se também nas escolhas e demandas do mercado editorial, assim como na carência de obras de escritores/as negros/as (constatação que, em 2016, deu origem à editora Malê) ${ }^{14} \mathrm{e}$, ainda, de personagens e narradores negros, como revelou a pesquisa "Quando o preconceito se faz silêncio: relações raciais na literatura brasileira contemporânea", de Regina Dalcastagnè (2008):

A literatura contemporânea reflete, nas suas ausências, talvez ainda mais do que naquilo que expressa, algumas das características centrais da sociedade brasileira. É o caso da população negra, que séculos de racismo estrutural afastam dos espaços de poder e de produção de discurso. Na literatura, não é diferente. São poucos os autores negros e poucas, também, as personagens - uma ampla pesquisa com romances das principais editoras do país publicados nos últimos 15 anos identificou quase $80 \%$ de personagens brancas, proporção que aumenta quando se isolam protagonistas ou narradores (Dalcastagnè, 2008, p. 204).

O estudo de Dalcastagnè analisou um corpus de 258 romances correspondentes à totalidade das primeiras edições de romances de autores brasileiros publicados por três grandes editoras (Companhia das Letras, Record e Rocco) e, entre os resultados, apontou ainda que, ao todo, foram publicados 165 escritores diferentes nos 15 anos abrangidos pela pesquisa, sendo que os homens representam $72,7 \%$ do total de autores publicados. Mais do que a desigualdade de gênero visível nos números de publicações de homens e de mulheres, a desigualdade racial (ou homogeneidade racial, dependendo do ponto de vista) é ainda mais discrepante: "são brancos $93,9 \%$ dos autores e autoras estudados (3,6\% não tiveram a cor identificada e os 'não-brancos', como categoria coletiva, ficaram em meros 2,4\%)" (Dalcastagnè, 2008, p. 206).

Esses números evidenciam a perpetuação de vozes e discursos hegemônicos e, em contrapartida, expõem a exclusão e o silenciamento de vozes de escritores e escritoras afrobrasileiras, situação relatada e vivenciada por Cristiane Sobral ao tentar publicar suas obras. Conforme constata Fredric Jameson (1992, p. 78), as vozes que se opõem a esses discursos hegemônicos, que buscam visibilizar uma perspectiva representativa da alteridade, são em grande parte "abafadas e reduzidas ao silêncio, marginalizadas, cujas palavras foram espalhadas pelo vento ou reintegradas na cultura hegemônica". Então, quando Sobral se recusa a atender às solicitações das editoras para modificar seu texto, não cedendo às recomendações para retirar trechos feministas ou de reafirmação da identidade afrodescendente, está também, de alguma forma, reiterando sua poética e resistindo como mulher, como negra e como escritora frente a esse contexto social e histórico de tentativas de silenciamento e exclusão.

\section{A poética afro-brasileira de Cristiane Sobral}

Em seu artigo intitulado "Literatura e afrodescendência: um conceito em construção", Eduardo de Assis Duarte (2008) constrói uma reflexão a respeito do debate sobre a consolidação acadêmica da literatura afro-brasileira como um campo específico de produção literária e sobre a multiplicidade e diversidade das produções literárias identificadas dessa forma. No estudo, o autor indaga sobre as especificidades e os elementos da escrita afro-brasileira que tornariam possível sua distinção em relação ao conjunto das letras nacionais. Sobre essa questão, Duarte

\footnotetext{
${ }^{14}$ No Brasil, temos também outras iniciativas semelhantes à da Malê, que têm se dedicado a visibilizar obras de autores e autoras afro-brasileiras, africanas ou da diáspora. Entre elas, podemos citar: Mazza Edições (Belo Horizonte), Ferinas (São Paulo), Padê Editorial (Brasília), Selo Negro Edições (São Paulo), Língua Geral (Rio de Janeiro), Quilombhoje (responsável pela publicação dos célebres Cadernos Negros).
} 
afirma que existem algumas constantes discursivas que se destacam como critérios de configuração dessa literatura, entre elas: a temática, sendo o sujeito negro o tema principal da literatura negra; a autoria, uma escrita de autor afro-brasileiro; e o ponto de vista, ou seja, faz-se necessário assumir uma perspectiva ou uma visão de mundo relacionada à história e à cultura negra. Além dessas três constantes, o autor ressalta a importância da linguagem, ligada à constituição de uma discursividade e vocabulários particulares, e, ainda, da formação de um público-leitor afrodescendente.

É importante destacar, no entanto, que esses elementos distintivos da literatura afrobrasileira não podem ser tomados de maneira isolada: temática, autoria, ponto de vista, linguagem e público-leitor não são suficientes para determinar o pertencimento à literatura afro-brasileira, devendo, portanto, os elementos serem considerados em suas interações e não isoladamente. Segundo o autor, a partir da conjunção e interação desses cinco principais fatores de diferenciação (tal como podem ser observados na obra de Sobral), é possível constatar, então, a existência da literatura afro-brasileira, bem como seus mecanismos de distinção em relação à literatura brasileira em geral.

Conforme destaca Duarte ${ }^{15}$ (2008), a literatura afro-brasileira é uma produção que está, simultaneamente, dentro e fora da literatura brasileira - dentro, porque faz uso da mesma língua, formas, gêneros e procedimentos de expressão; fora, principalmente porque não se enquadra na missão romântica da literatura brasileira de instituição de um "espírito nacional". A literatura afro-brasileira está, antes de tudo, empenhada em construir uma escritura que, mais do que expressar a arte e a cultura produzida pelos afrodescendentes, aponte o etnocentrismo e a consequente exclusão dos negros do universo das letras e da própria civilização ocidental. De acordo com Duarte (2008, p. 22, grifo do autor), vem daí "seu caráter muitas vezes marginal, porque fundado na diferença que questiona e abala a trajetória progressiva e linear da historiografia literária canônica".

Em Terra Negra, Cristiane Sobral utiliza-se dos cinco elementos apontados por Duarte (temática, autoria, ponto de vista, linguagem e público-leitor), construindo sua estética e seus poemas de maneira a falar sobre a realidade da mulher negra a partir de sua própria subjetividade, utilizando, para tanto, uma linguagem e escolhas vocabulares próprias. Da mesma forma, também assume uma perspectiva e uma visão de mundo ligadas à sua história e às suas experiências como mulher negra e direciona sua escrita para homens e mulheres negros e negras, ainda que esses, obviamente, não possam nem devam ser seus únicos leitores.

Nas palavras que compõem o prefácio à obra de Cristiane Sobral, Elisa Lucinda qualifica o texto da autora como uma escrita de tribo, refletindo como seus textos trazem em si uma coletividade, representativa das histórias e das experiências da escritora, mas também de tantas outras mulheres negras e de uma comunidade afro-brasileira. Para Lucinda:

A voz de uma mulher negra é a voz que se nega ao silenciamento, a voz que se impõe à porta da casa grande e entra. Arrebenta a tranca e ainda tem que provar, a cada balcão, o que é, quem é, e porque o é. Cansa até. Como a poesia é feita do impacto entre a poeta ou o poeta e sua experiência de viver, está presente todo o tempo, nas escuridões de Terra negra, a luta existencial de todas nós (Lucinda, 2017, p. 12-13).

A perspectiva de Cristiane Sobral visibiliza vozes e histórias negras, invisibilizadas em meio à homogeneização de autores, personagens e narradores brancos. Como afirma Lucinda (2017, p. 13), "é a voz de uma pele preta, é o testemunho transafricano de um existir ainda raro no mundo da literatura apinhada de galegas princesas e iguais reis". Para aprofundarmos a discussão sobre a literatura de Sobral, analisaremos, na sequência e mais detalhadamente, um dos poemas presentes em Terra Negra, de maneira a compreendermos como ele é representativo da construção literária e poética afro-brasileira da autora.

\footnotetext{
${ }^{15}$ Sobre essa discussão, ver também Duarte $(2007 ; 2014)$.
} 


\section{Um poema-testemunho em Terra Negra: uma leitura de "350 metros"}

Vários são os temas abordados nos poemas de Terra Negra, destacando-se, por exemplo, a luta e a resistência de homens e mulheres negros/as, a insubmissão e o empoderamento feminino, o racismo e a desigualdade social e econômica, o genocídio negro e a violência policial. Através da leitura dos poemas, também foram identificadas uma série de referências à África (religiosidade, orixás, ancestralidade, termos e expressões linguísticas), o erotismo a partir da perspectiva da mulher negra, as experiências e representações dessa mulher perpassando discussões sobre identidade, negritude, sexualidade, amor, estética/beleza, liberdade e autonomia, objetificação sexual do corpo negro, a solidão da mulher negra. Vários desses grandes temas inter-relacionam-se na construção poética de "350 metros":

\section{0 metros $^{16}$}

1. Eu fui ao inferno

2. lavar o corpo de minha filha

3. O abismo é branco meus senhores

4. Minha filha foi jogada lá

5. 350 metros

6. 350 metros

7. Eu fui pedir ao bispo do palácio dos martírios

8. Ele que desse outra chance à minha filha

9. Queria colocar Cláudia de novo

10. em meu útero

11. Ela merecia outra chance de nascer

12. Como eu sofri no meio daquela branquitude

13. Eu gritei em vão por Cláudia

14. Filha, filha!

15. A Cláudia saiu das minhas entranhas,

16. Das minhas entranhas pretas!

17. Minha menina foi arrastada e morta

18. 350 metros

19. 350 metros meus senhores!

20. Eu vi!

21. Toda aquela brancura

22. Misturada aos pedaços do corpo

23. De minha filha

24. Eu vi!

25. Eu vi!

26. $\mathrm{Vi}$

27. Toda aquela brancura

28. Misturada com o sangue de minha filha

29. sem a menor culpa (Sobral, 2017, p. 88-89).

Ao longo da obra, Sobral relata diversas experiências como mulher negra e, nesse poema, apropria-se de um caso real como matéria literária para sua construção poética. ${ }^{17}$ Nesses versos,

\footnotetext{
${ }^{16}$ Os versos não aparecem numerados na versão original do poema. A numeração foi aqui incluída para facilitar a retomada dos versos discutidos ao longo da análise neste trabalho.

${ }^{17}$ Assim como em "350 metros", o recurso de apropriar-se de acontecimentos reais para a construção de seus poemas também pode ser observado em "Acertando as contas" (Sobral, 2017, p. 58), que aborda a história real de Amarildo Dias de Souza, a partir da construção de um eu-lírico representado por seu filho. Amarildo era negro, pobre, ajudante de pedreiro, morador de uma favela no Rio de Janeiro, e está desaparecido desde o dia 14 de julho de 2013, após ter sido detido por policiais militares na Favela da Rocinha (RJ) e conduzido até a Unidade de Polícia Pacificadora (UPP) da comunidade. O caso de Amarildo representa um símbolo de
} 
especificamente, a autora aborda a história de Cláudia Silva Ferreira, morta no dia 16 de março de 2014 durante uma operação da Polícia Militar. Cláudia era auxiliar de serviços gerais, moradora do Morro da Congonha, zona norte do Rio de Janeiro. Mulher negra, 38 anos de idade, em um momento em que havia saído para comprar pão para a família, Cláudia foi baleada em uma "troca de tiros entre traficantes e a polícia" na comunidade em que vivia com seu marido, seus quatro filhos e quatro sobrinhos. Após ser baleada, Cláudia foi levada a uma viatura de polícia e colocada no porta-malas. Durante o trajeto, o porta-malas abriu, os policiais não pararam o carro e Cláudia foi arrastada por aproximadamente 350 metros, seminua e presa ao porta-malas da viatura apenas por um pedaço da roupa.

Toda essa situação foi filmada por pedestres e motoristas de outros carros que transitavam pela Estrada Intendente Magalhães (RJ) e, pela violência absurda das imagens, logo repercutiu em grupos do aplicativo WhatsApp e ganhou amplo destaque nos noticiários nacionais. No entanto, a mídia tradicional tratou o caso de maneira superficial, sensacionalista e sem maiores problematizações, divulgando o fato com manchetes que continham, com pequenas variações, $\mathrm{o}$ seguinte título: "mulher arrastada por viatura da PM" - sem o nome ou sobrenome, sem identificação, sem conferir identidade à vítima. Também se repetiam termos como "filhos da arrastada" e "família de mulher arrastada". Uma pesquisa desenvolvida por Arianne de Lima (2015) abordou a construção da representação de Cláudia Silva Ferreira a partir dos discursos de três jornais de grande circulação nacional (Folha de São Paulo, Estado de São Paulo e O Globo), analisando a construção de sentidos em reportagens veiculadas na época e o descaso implícito na cobertura jornalística como efeitos decorrentes do racismo e do preconceito de classe.

Na cobertura da mídia, tratava-se apenas de mais uma mulher negra e pobre morta pela polícia, transformada em estatística. No poema "350 metros", o que percebemos imediatamente - e que destoa sensivelmente da representação tradicional do caso na mídia - é justamente a presença do nome da vítima: "Cláudia", repetido três vezes ao longo do poema (nos versos 9, 13 e 15). Ressalta-se, com a utilização desse recurso poético, a necessidade de conferir história e identidade à vítima da violência policial, no poema e também na vida real. Nos versos de Sobral, Cláudia é vista como sujeito e como ser humano. Nesse sentido, a importância de nomeá-la está diretamente relacionada à sua humanização. ${ }^{18}$

São três as principais estratégias que permitem a identificação do poema com a história real de Cláudia: a primeira é justamente sua nomeação (e a repetição desse nome por três vezes ao longo do poema); a segunda é a revelação das circunstâncias da morte de Cláudia - "Minha menina foi arrastada e morta" - (verso 17, grifos nossos); e a terceira é a indicação com o detalhamento da distância percorrida pela viatura policial com a vítima sendo arrastada. Destaca-se que, na época, esses números foram amplamente divulgados pela mídia, com pequenas variações na distância. Nesse caso, além do título do poema de Sobral, a expressão "350 metros" também é reiterada por quatro vezes ao longo do poema (nos versos 5, 6, 18 e 19).

Em "350 metros", o eu-lírico é representado pela mãe de Cláudia e a sua voz poética também de mulher negra e mãe, tal como a filha - não se cala diante de tamanha violência, arbitrariedades e injustiças, gritando ao mundo o crime cometido pela Polícia Militar. É a partir da voz da mãe de Cláudia que a sua história é contada ou rememorada: ao longo do poema, a mãe revela, em primeira pessoa, o que viu e vivenciou, particularmente a ida ao Instituto Médico Legal para lavar e reconhecer o corpo da filha, a ida à Igreja para rogar inutilmente por outra chance para Cláudia, o desejo de gestá-la novamente na tentativa de conceder-lhe uma nova vida e um destino diferente daquele, o sofrimento em meio à "branquitude", o horror de

desaparecimentos não esclarecidos pela Polícia Militar. A campanha Onde está Amarildo?, iniciada nas redes sociais, com o apoio de movimentos como o Rio de Paz, as Mães de Maio e a Rede de Comunidades e Movimentos contra a Violência, mobilizou o grande público e alcançou repercussão internacional.

${ }^{18}$ Também com a intenção de evitar o sensacionalismo e promover a humanização da vítima, a organização não governamental (ONG) Think Olga criou o Projeto 100 vezes Cláudia, buscando retratá-la a partir de olhares e imagens sensíveis de artistas de todo o país. Em 24 horas do lançamento do Projeto, o site da ONG conseguiu mais de 100 homenagens, as quais foram expostas no Museu da Cia. Paulista e estão disponíveis em https://thinkolga.com/2014/03/19/100-vezes-claudia/. Como as contribuições continuaram a chegar, foi necessário criar uma segunda página, intitulada Mais 100 vezes Cláudia, disponível em: https://olgaproject.herokuapp.com/2014/03/22/mais-100-vezes-claudia/. 
conhecer os detalhes da morte e da violência sofrida, a ausência de sentimentos de culpa nos responsáveis pelo crime, a indignação frente à impunidade.

Para a análise literária do poema de Sobral, trabalharemos com o que, por ora, denominaremos de poema-testemunho - categoria aqui empregada como resultado das reflexões e discussões sobre a literatura de testemunho, particularmente sobre a vertente latino-americana. ${ }^{19} \mathrm{O}$ poema-testemunho relaciona-se com a literatura de testemunho na medida em que promove uma emulação desse processo, constituindo-se a partir da inter-relação entre aspectos documentais e históricos, fatos reais e elementos ficcionais. A autora apropria-se do funcionamento e da concepção das narrativas de testemunho para aplicar suas estratégias e recursos na escritura do poema. Assim, constituindo-se a partir da conjugação, ao mesmo tempo, de elementos ficcionais e referenciais, o poema-testemunho busca fazer emergir vozes silenciadas, como uma forma de resistência e de questionamento da "história oficial" - no caso desse poema, uma voz que se ergue contra a impunidade policial em mais uma morte de uma mulher, negra, pobre, moradora de uma comunidade carioca.

Por meio de uma experiência pessoal, o poema-testemunho representa não apenas o indivíduo singular, mas, principalmente, a experiência de uma coletividade. Em "350 metros", o sujeito poético narra sua experiência própria - o caso singular da morte de Cláudia - mas também articula as experiências de tantas mães e mulheres que perdem seus filhos e filhas pela violência policial ou como consequência de discriminação de raça. ${ }^{20}$ Ao refletir sobre essa questão, Alós (2009, p. 146) destaca, como papel fundamental desse tipo de narrativa, "denunciar uma experiência de opressão e/ou exclusão, assim como o de desvelar e desautorizar a história oficial como sendo 'A Verdade', abrindo caminho para outras vozes e outras versões de determinados fatos sociais". Ou seja, ao abrir espaço para vozes silenciadas (particularmente, pela mídia na cobertura do caso), a literatura de testemunho possibilita uma espécie de confronto ou questionamento da história oficial, fazendo com que outra versão, partindo de um eu-lírico representado pela mãe de Cláudia, alcance o coletivo.

Com uma postura de não silenciamento e de resistência/enfrentamento, o sujeito poético relembra os acontecimentos - com um discurso em primeira pessoa do singular e utilizando os verbos no passado -, testemunhando, denunciando e acusando ao mesmo tempo. O poematestemunho de Sobral constitui-se, dessa maneira, como uma forma de não deixar cair no esquecimento o homicídio de Cláudia, além de evocar a memória do caso - lembrando os pormenores pós-morte, configura-se também como uma forma de lutar por justiça para a filha ${ }^{21}$ e, de maneira mais ampla, para outros casos de violência policial contra a população negra.

Essa rememoração, por mais que traga dor e sofrimento à mãe - perceptível no uso de termos como "Eu fui ao inferno lavar o corpo de minha filha" (verso 1), "Como eu sofri no meio daquela branquitude" (verso 12), "Eu gritei em vão por Cláudia" (verso 13), "Minha menina foi arrastada e morta" (verso 17) -, é compreendida como necessária na busca por justiça. Conforme explicação de Márcio Seligmann-Silva, as vítimas de eventos traumáticos buscariam a memória, a narração e uma espécie de esquecimento do trauma, no sentido de afastamento da dor. Para o autor, essas pessoas necessitam "narrar, elaborar e esquecer" seus traumas, sendo o esquecimento também buscado, porque elas "são assombradas pelo sofrimento desses males e não para apagar as atrocidades e, muito menos, negar um sentimento de justiça" (Seligmann-Silva, 2013, p. 133).

\footnotetext{
${ }^{19}$ Principalmente a partir da segunda metade do século XX, aflora na América esse novo gênero literário. Conforme destaca Alós (2009, p. 141, grifo do autor), "a narrativa de testemunho, também chamada de literatura de depoimento, nasceu da necessidade de se expressar a opressão dos grupos subalternos em um contexto de ferrenhas ditaduras nos Estados Nacionais latino-americanos". Esse gênero foi adotado especialmente por escritoras comprometidas com questões políticas do século XX, ressaltando-se obras como Si me permiten hablar... (traz o testemunho de Domitila Barrios de Chungara para Moema Viezzer, um relato da exploração e da luta da classe operária boliviana publicado originalmente em 1977) e Me llamo Rigoberta Menchú y así me nació la conciencia (apresenta o testemunho da indígena guatemalteca Rigoberta Menchú, transcrito por Elizabeth Burgos-Debray e publicado originalmente em 1983).

${ }^{20}$ Como um dos casos mais recentes da violência policial, no dia 20 de junho de 2018, uma operação da Polícia Civil com o apoio do Exército no Complexo da Maré, no Rio de Janeiro, resultou na morte de Marcos Vinícius da Silva, um adolescente de 14 anos, atingido por um tiro quando se dirigia para a escola onde estudava.

${ }^{21}$ Vale lembrar, ainda, que o crime foi cometido em 2014 e, seis anos depois, os dois policiais militares acusados pela morte de Cláudia ainda não foram julgados - e, inclusive, segundo informações do jornal Extra, estão envolvidos em outras oito mortes registradas como homicídios decorrentes de intervenção policial (PMS..., 2018).
} 
Ao longo do poema, são traçados alguns sinais que evocam os possíveis responsáveis pela morte de Cláudia. Ainda que não acusadas direta e explicitamente, algumas instituições podem ser compreendidas como tendo responsabilidade ou como sendo complacentes ou omissas em relação aos eventos que levaram ao homicídio, demonstrando que a discussão sobre o texto é bastante complexa. De maneira mais ampla, a responsabilidade - explícita ou implícita - sobre a morte de Cláudia recai sobre instituições da "branquitude", podendo, aqui, ser interpretadas como espaços físicos e/ou ideológicos. Os possíveis espaços físicos da branquitude insinuados no poema seriam, em primeiro lugar, o Instituto Médico Legal, lugar onde no início do poema (versos 1, 2 e 3) o sujeito poético vai para encontrar o corpo da filha ("Eu fui ao inferno / lavar o corpo de minha filha / O abismo é branco meus senhores"). O "branco" que esse espaço evoca vai além dos efeitos das luzes claras do lugar, dos jalecos e das próprias paredes, representando também o branco da identidade étnico-racial (privilegiada) dos próprios profissionais que, em sua maioria, atuam nesses lugares.

Como um segundo espaço físico presente no poema, no verso 7 ("Eu fui pedir ao bispo do palácio dos martírios"), estão as instituições católicas, na figura de um de seus representantes, local ao qual o sujeito poético recorre, inutilmente, com a esperança de pedir uma nova chance para a vida de Cláudia. Sobre essa segunda instituição mencionada, é importante recordar como a Igreja construiu discursos que promoveram a legitimação da escravidão. Conforme destaca Abdias Nascimento (2017), "a Igreja Católica também considerava o [sangue] do negro como um 'sangue infectado'", contribuindo para o endosso religioso de diversas formas de violência, como o processo de miscigenação e de exploração sexual da mulher negra em uma tentativa de embranquecer a população negra no país durante o século XIX.

Por último, também de maneira implícita, evoca-se a responsabilidade da instituição militar, principalmente através das referências que possibilitam sua identificação com o caso real, ou seja, por meio da nomeação da vítima, do número que revela a distância percorrida pela viatura arrastando o corpo de Cláudia e da revelação das circunstâncias da morte. A partir do poema de Sobral, também é possível evocar a responsabilidade e/ou complacência ou omissão do Estado diante do caso, assim como de tantos outros semelhantes, ${ }^{22}$ pautando a discussão sobre um processo de genocídio negro institucionalizado no país. De acordo com Florestan Fernandes (2017, p. 19), "da escravidão, no início do período colonial, até os dias que correm, as populações negras e mulatas têm sofrido um genocídio institucionalizado, sistemático, embora silencioso".

Para o autor, vem acontecendo, no Brasil, "um genocídio insidioso, que se processa dentro dos muros do mundo dos brancos e sob a completa insensibilidade das forças políticas que se mobilizaram para combater outras formas de genocídio" (Fernandes, 2017, p. 20, grifo do autor). No poema de Sobral, alguns versos remetem a essa discussão e a esse "mundo dos brancos" destacado por Fernandes, principalmente quando a voz poética faz uso de expressões como "O abismo é branco" (verso 3), "Como eu sofri no meio daquela branquitude" (verso 12), "Toda aquela brancura / misturada aos pedaços do corpo" (versos 21 e 22) e "Toda aquela brancura / Misturada com o sangue de minha filha / sem a menor culpa" (versos 27, 28 e 29). O branco, que geralmente é associado à pureza, à limpeza e à inocência na tradição literária ocidental (particularmente na lírica), nesses versos, provoca o efeito contrário, relacionando-se ao inferno, ao homicídio cometido, ao horror, ao sofrimento, à violência de espaços que são, simultaneamente, físicos e ideológicos.

Por trás desse processo de genocídio, esconde-se um racismo institucionalizado com consequências perceptíveis em vários segmentos da sociedade brasileira. Conforme explica Nascimento (2017), o mito da "democracia racial" no país é a metáfora ideal para designar o racismo ao estilo brasileiro. No entanto, no contexto nacional, esse racismo é "institucionalizado de forma eficaz nos níveis oficiais de governo, assim como difuso e profundamente penetrante no tecido social, psicológico, econômico, político e cultural da sociedade do país" (Nascimento, 2017, p. 111). O poema-testemunho de Sobral, a partir de uma voz poética negra que se recusa a ocupar um lugar de silêncio, desvela também essa violência institucionalizada, física e ideológica, direcionada à população negra brasileira, assim como reitera que a resistência e a

\footnotetext{
${ }^{22}$ Uma pesquisa feita pelo Instituto de Segurança Pública, em 2017, a partir de dados obtidos através da Lei de Acesso à Informação, mostrou que nove em cada dez mortos pela polícia no Rio de Janeiro são negros ou pardos (Bianchi, 2017).
} 
construção poético-literária continuam sendo recursos fundamentais para a luta, para a memória e para uma possível transformação dessa realidade.

\section{Considerações finais}

Neste estudo, buscamos trazer algumas reflexões a respeito das relações que perpassam os campos da literatura e do mercado editorial, assim como os aspectos complexos que se colocam nesse embate, como os valores estéticos, ideológicos, políticos, históricos e econômicos que interferem na publicação, ou não, de determinadas obras ou de determinados autores/as. Em meio às determinações do mercado, surgem também, e cada vez mais, iniciativas individuais ou de pequenos grupos editoriais, que procuram encontrar seus espaços singulares para inserção, circulação e expansão, como é o caso da Editora Malê. Essa editora, desde 2016, tem colaborado com a ampliação da diversidade no mercado editorial, visibilizando obras de escritores e escritoras negros/as, inclusive com a publicação do livro de poemas Terra Negra (2017), de Cristiane Sobral, foco da análise deste artigo.

Tanto a Malê quanto a obra de Sobral em questão são representativas de uma tentativa de incentivo para que o leitor perceba elementos e contextos que estão além do livro propriamente dito, sem que essa atitude implique uma atenção menor ao texto literário em si. Trata-se, no entanto, de manter um olhar atento e compreender que as obras literárias estão situadas em um contexto sociocultural mais amplo e em uma determinada historicidade, assim como são resultantes de interrelações entre autores, leitores e intermediários nesse processo. Nessas inter-relações é que se constituiu o livro Terra Negra, em meio às dificuldades de inserção, de distribuição e de divulgação de uma obra de poesias no mercado editorial, somadas aos silenciamentos históricos de escritoras mulheres e negras, baseados em discriminações de gênero e de raça.

Transpondo essas dificuldades e esse contexto, Sobral visibiliza vozes e histórias negras, a partir de suas experiências e de sua subjetividade, abordando temas como a insubmissão e o empoderamento feminino, o racismo e a desigualdade social, o genocídio da população negra, a violência policial, a objetificação sexual da mulher, a reafirmação da identidade negra, a luta e a resistência constante de homens e mulheres negros/as. Entre os poemas que constituem Terra Negra, neste estudo analisamos "350 metros", no qual a autora se apropria de um caso real para a sua construção poética, construindo uma leitura baseada principalmente em uma denominação própria: o poema-testemunho. Para tanto, relacionamos esse novo gênero com a literatura de testemunho, particularmente com a vertente latino-americana, adotada principalmente por escritoras notadamente comprometidas com questões políticas.

Compreendemos o poema-testemunho como uma forma de construção poética que se constitui a partir da conjugação de aspectos históricos referenciais (a morte de Cláudia Silva Ferreira pela polícia militar em uma comunidade no Rio de Janeiro, no ano de 2014) e elementos ficcionais (o sujeito poético representado pela mãe de Cláudia, que narra suas experiências e constrói seu testemunho a partir de seu ponto de vista ao longo do poema). Por fim, consideramos esse poema particularmente representativo tanto da estética literária da autora, como também do projeto estético e da linha editorial defendida pela editora Malê, na medida em que busca fazer emergir vozes negras silenciadas (no poema, em específico, e no campo literário e editorial, de maneira mais ampla), constituindo-se como uma forma de apropriação literária para visibilizar, representar e construir novas - e diferentes - poéticas.

\section{Referências}

ADORNO, Theodor W. (1949/2002). Crítica cultural e sociedade. In: ADORNO, Theodor W. Indústria cultural e sociedade. Tradução de Júlia Elisabeth Levy. 5. ed. São Paulo: Paz e Terra. p. 45-61.

ALÓS, Anselmo Peres (2009). Literatura e intervenção política na América Latina: relendo Rigoberta Menchú e Carolina Maria de Jesus. Cadernos de Letras da UFF, n. 38, p. 139-162. Disponível em: https:// bit.ly/32LHj9N. Acesso em: $1^{\circ}$ jul. 2018. 
ALÓS, Anselmo Peres (2011). Histórias entrelaçadas: redes intertextuais em narrativas afro-brasileiras. Cerrados, v. 20, n. 31, p. 107-122. Disponível em: https:// bit.ly/3lElhOH. Acesso em: 27 jun. 2018.

AMARO, Vagner (2016). Nova no mercado, Malê promove escritores afro-brasileiros. [Entrevista cedida a] Bolívar Torres. O Globo, Rio de Janeiro, 19 nov. On-line. Disponível em: https://glo.bo/2YU2rJT. Acesso em: 26 nov. 2018.

BIANCHI, Paula. 9 em cada 10 mortos pela polícia no Rio são negros ou pardos. Uol Notícias, 26 jul. 2017. On-line. Disponível em: https:/ / bit.ly/2ZaSYOy. Acesso em: 27 jun. 2018.

BURGOS-DEBRAY, Elizabeth; MENCHÚ, Rigoberta (1991). Me llamo Rigoberta Menchú y así me nació la conciencia. La Habana: Casa de las Américas.

CANCLINI, Néstor Garcia (2016). O mundo inteiro como lugar estranho. São Paulo: EdUSP.

COMPAGNON, Antoine (2001). O demônio da teoria: literatura e senso comum. Belo Horizonte: Ed. UFMG.

CUTI, Luiz Silva (2010). Literatura negro-brasileira. São Paulo: Selo Negro.

DALCASTAGNÈ, Regina (2008). Quando o preconceito se faz silêncio: relações raciais na literatura brasileira contemporânea. Gragoatá, Niterói, n. 24, p. 203-219.

DUARTE, Eduardo de Assis (2007). Machado de Assis afro-descendente: escritos de caramujo. Rio de Janeiro: Pallas; Belo Horizonte: Crisálida.

DUARTE, Eduardo de Assis (2008). Literatura e afrodescendência: um conceito em construção. Estudos de Literatura Brasileira Contemporânea, Brasília, n. 31, p. 11-23. Disponível em: https://bit.ly/32FLhAE. Acesso em: 28 jun. 2018.

DUARTE, Eduardo de Assis (2014). Literatura afro-brasileira: 100 autores do século XVIII ao XXI. Rio de Janeiro: Pallas.

EAGLETON, Terry (2006). Teoria da literatura: uma introdução. Tradução de Waltensir Dutra. 6. ed. São Paulo: Martins Fontes.

FERNANDES, Florestan (2017). Prefácio à edição brasileira. In: NASCIMENTO, Abdias. O genocídio do negro brasileiro: processo de um racismo mascarado. 2. ed. São Paulo: Perspectiva. p. 17-21.

HORKHEIMER, Max; ADORNO, Theodor W. (1947/2002). O Iluminismo como mistificação das massas. In: ADORNO, Theodor W. Indústria cultural e sociedade. Tradução de Júlia Elisabeth Levy. 5. ed. São Paulo: Paz e Terra. p. 5-44.

JAMESON, Fredric (1992). O inconsciente político: a narrativa como ato socialmente simbólico. Tradução de Valter Lellis Siqueira. São Paulo: Ática.

LEONE, Luciana di (2014). Poesia e escolhas afetivas. Rio de Janeiro: Rocco.

LIMA, Arianne de (2015). A "mulher arrastada": a construção da representação do Caso Cláudia Silva Ferreira em três jornais da região Sudeste do Brasil. 56 f. Trabalho de Conclusão de Curso (Graduação em Comunicação Social - Jornalismo) - Universidade Federal de Santa Maria, Santa Maria.

LUCINDA, Elisa (2017). A Carta da Terra. In: SOBRAL, Cristiane. Terra Negra. Rio de Janeiro: Malê. p. $12-17$.

MACHADO, Renata Mendonça (2008). A literatura no mercado editorial: um estudo da visão comercial sobre a literatura. 59 f. Trabalho de Conclusão de Curso (Graduação em Comunicação - Produção Editorial) Escola de Comunicação, Universidade Federal do Rio de Janeiro, Rio de Janeiro.

NASCIMENTO, Abdias (2017). O genocídio do negro brasileiro: processo de um racismo mascarado. 2. ed. São Paulo: Perspectiva.

PETERSON, Michel (1995). Estética e política do romance contemporâneo. Porto Alegre: Editora da UFRGS.

PMS acusados pela morte de Claudia, arrastada por viatura, se envolveram em oito homicídios desde 2014 (2018). Extra, Rio de Janeiro, 16 mar. Disponível em: https://glo.bo/3buF4eU. Acesso em: 22 maio 2020.

SELIGMANN-SILVA, Márcio (2013). Direito pós-fáustico: por um novo tribunal como espaço de rememoração e elaboração dos traumas sociais. In: CORNELSEN, Élcio Loureiro et al. (Orgs.). Literatura e cinema de resistência. Rio de Janeiro: Oficina Raquel. 
SHOHAT, Ella; STAM, Robert (2006). Crítica da imagem eurocêntrica: multiculturalismo e representação. Tradução de Marcos Soares. São Paulo: Cosac Naify.

SOBRAL, Cristiane (2017). Terra Negra. Rio de Janeiro: Malê.

SOBRAL, Cristiane (2018). Entrevista concedida a Camila Marchesan Cargnelutti. E-mail, 9 maio 2018.

VIEZZER, Moema; CHUNGARA, Domitila Barrios (1977). Si me permiten hablar... testimonio de Domitila, una mujer de las minas de Bolivia. La Paz: Siglo XXI. 